\title{
Evaluation of Nanomaterials for Building Production within the Context of Sustainability
}

\author{
Ahmad Zeyad Aljenbaz ${ }^{1}$, Assist. Prof. Dr Çiğdem Çağnan ${ }^{2}$
}

\begin{abstract}
Nanotechnology is a new technology created by manipulating small particles in the material in order to obtain different and unique properties. It brings new solutions in economic, ecologic and social ways to participate in achieving sustainability. Nanomaterials, which are the products of this new technology, are used in building construction field with the aim of reducing the harm to the environment. The aim of this paper is to determine the effects of nanomaterials in this field. To reach the aim of the study, the topic was examined in the following sequence. Firstly, the general definition of nanotechnology and dimensional classification of nanomaterials were made. Nanotechnology, nanomaterial and nanoarchitecture applications in building production were examined together with examples. The effects of different applications were analyzed in conjunction with environmental-social and economic sustainability issues. Finally, the nanomaterials were evaluated within a test and evaluation matrix according to the environmental-social-economical sustainability criteria. Evaluation was made through the percentages of effects where $(+)$ has positive effect, $(-)$ has negative effect and (o) has no/unknown effect. The test results were explained in a test evaluation report. The findings of the research from the test results point out that, the use of nanomaterials in building production can help to achieve sustainability but the effects on human health have not been fully determined yet and this is the most important disadvantage of using these new tech materials.
\end{abstract}

Keywords: Sustainability; nanotechnology; nanoarchitecture; nanomaterials; building production; test evaluation matrix

\section{Introduction}

Nanotechnology, shortened to nanotech is called to the science which produces materials on a very small scale. It is a new multidisciplinary science. The relation between this new technology and architecture is with materials science. Nanomaterials are developed through nanotechnology in order to obtain specific performances like selfcleaning windows, self-healing concrete, light emitting surfaces, flexible solar panels and anti-bacterial coatings. In this paper, it gives a look at the beneficial bonds between nanotechnology, architecture and nanomaterials on the scale of molecules and sustainability. It concludes with analysis and evaluation of nanomaterials that can be recommended in order to help the development of nanotechnology to grow green and participate in sustainability.

\subsection{Problem}

In 1987, the United Nations World Commission on Environment and Development (UN-WCED) presented a report entitled 'Our Common Future' which became known as the Brundtland Report. The concept of 'Sustainable Development' has been put

${ }^{2}$ Near East University, Faculty of Architecture, Department of Architecture, North Cyprus. 
forward for the first time in the report based on the concerns about the worsening situation in all areas of life. It stated that, sustainable development meets the needs of the present without compromising the ability of future generations to meet their own needs [1].

Due to environmental problems such as global warming and pollution, scientists are looking for solutions to ensure sustainability. Can nanotechnology help to solve this global problem? To find an answer for this question is the main reason of carrying out this research.

The professions which work on the buildings have hesitated to use this new technology in building production because of the lack of knowledge in new applications and their possibility to improve new building materials. Studying the advantages and disadvantages of using this technology in building production through different applications of nanomaterial building products is another important reason of conducting this research. This paper tries to explain the possibility of using nanomaterials in building production by an analysis table and test evaluation matrix according to environmental, social and economic sustainability criteria.

\subsection{Aim and objectives of the research}

Nanotechnology is the fastest improving technology of the $21^{\text {st }}$ century. Nanomaterials are the products of this new technology. Compared with traditional products they can be more durable, longer lasting, better quality, lighter and smaller. The main aim of this study is to find the positive, negative and ineffective/unknown effect ratios of nanomaterial applications in building production. The objectives are;

- Examine the properties of nanomaterials and their impacts on building and environment.

- Clarify the advantages and disadvantages of using nanomaterials and their effects to achieve sustainability, by analyzing the different applications in building production.

- Analyze and evaluate the different applications of nanomaterials in building production within the context of the environment, human health, energy and resource conservation by finding out the percentage ratios of different effects.

\subsection{Importance of the research}

Nanotechnology applications are new in architecture field and there is a lack of literature about this topic. Knowledge of nanotechnology applications in architecture, studying the advantages and disadvantages of nanomaterial applications in the buildings can help to solve environmental problems caused from buildings. They can help to reduce dependence on nonrenewable resources, improve the health system, and reduce energy use, decrease raw materials consumption, emissions of $\mathrm{CO}_{2}$ and save the natural resources.

\subsection{Methodology of the research}

The main material of this study is the nanomaterials used in building production. All the data onto this paper are collected according to the literature survey from primary sources such as books, journals, articles and internet sources. Literature review is done to collect data for analysis table and evaluation matrix. After literature review, a data bank is formed and analysis is made focusing on nanomaterials used in building production. In the analysis, the sustainability criteria and nanomaterial applications are identified and tested within a matrix by finding out the positive, negative and ineffective percentage ratios. The results are explained with an evaluation report. To reach the aim these steps 
are followed;

- Dimensional classification of nanomaterials in building production is made (Table 1).

- Different application scales are classified by dimensions and types (Figure 1).

- Nanoarchitecture applications in building production are investigated (Table 2).

- The advantages and disadvantages of nanomaterial applications are analyzed (Table 3).

- Architectural applications are tested within a matrix (Table 4). Evaluation is made through the percentages of effects (positive, negative and ineffective) ratio and results are explained with a test evaluation report.

\section{Definition of Nano}

The word nano, originates from Greek word meaning dwarf person. It implies one billionth and one nanometer $(1 \mathrm{~nm})$ is equal to one billionth of a meter $\left(10^{-9} \mathrm{~m}\right)$. Nano have three integral terms inside the range of nanotechnology which are: Nanoscale, Nanoscience and Nanotechnology (Loeve 2010).

Nanoscale is the scale which is based on nanometer $(\mathrm{nm})$ or $10^{-9}$ meter. This scale exists specifically between 1 and $100 \mathrm{~nm}$. Nanoscale materials usually have at least one dimension either height, length or depth within 1-999 nm (Richter et al. 2000; Berger 2010).

Nanoscience is the range of science where the size assumes an essential part at the time when matter size is beneath $100 \mathrm{~nm}$. It studies the performances of materials determining their chemical and physical properties.

Nanotechnology, shortened to nanotech is a new field of science, engineering and technology which studies the controlling of matter on an atomic and molecular scale. Generally, it involves in developing new materials and devices with structures in nanoscale. This new technology is a highly multidisciplinary field, applied in almost all aspects of life such as medicine, electronics, transportation, communications and industry (Schodek et al. 2009; Tamirat 2017).

\subsection{Nanomaterials}

Nanomaterials are the products of nanotechnology. They have at least one dimension either height, length or depth smaller than 100 nanometers. At this nanoscale they often exhibit extraordinary biological, physical and chemical properties. The regular way to classify nanomaterials through their dimensions is; zero dimensional (nanoparticles), one dimensional (nanowires, nanorods, nanotubes), two dimensional (nanocoatings, nanofilms) and three dimensional (nanocrystalline and nanocomposite) materials (Sagadevan 2013; Mohamed 2015). This classification (Table 1) basically depends on the different kind of dimensions, that is not related to the nanoscale size $(<100 \mathrm{~nm})$, while moving in these classifications from zero dimension to three dimensions, it becomes more and more hard to define as well (Leydecker 2008).

Table 1: Classification of nanomaterials in building production (Arcan 1999; Aljenbaz 2017) 


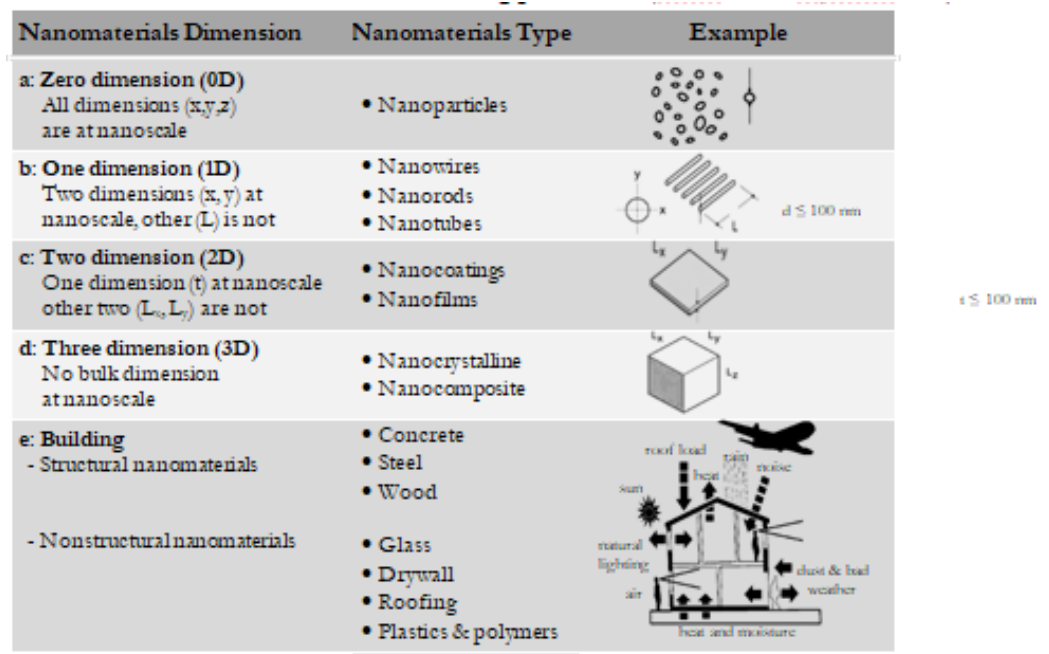

Nanomaterial's applications can be scaled by their dimensions and classified from the point of planning approach. As can be seen in Figure 1 when rising from bottom to top, the application scale also rises from nanomaterial scale to nano-city scale. From left to right, nanomaterials are classified from zero-dimension rising up to material product dimension. Cell ' $\mathbf{A}$ ' is the highest level achieved in the applications of nanomaterials which shows the city scale.

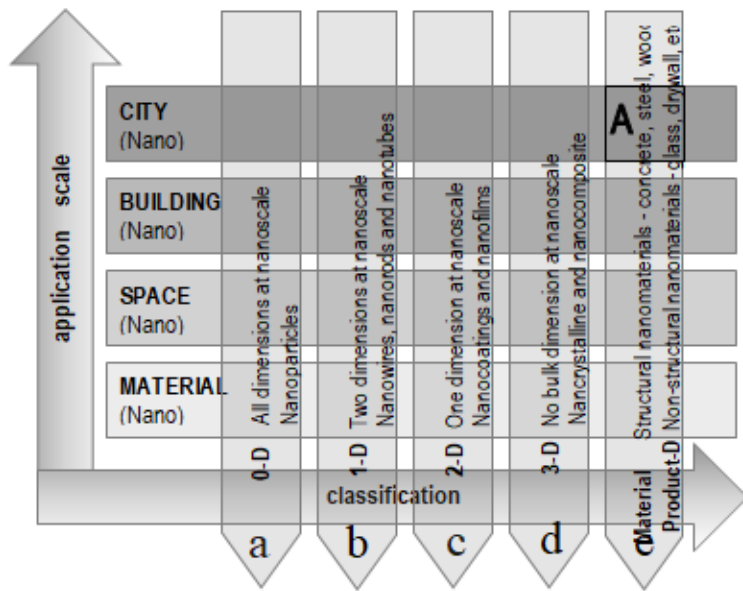

Figure 1: The applications of nanomaterials in different scales by dimensions and types

\subsection{Nanoarchitecture applications}

Nanoarchitecture is the combination of architecture with nanotechnology. The use of nanotechnology in architecture varies from materials, equipments to forms and design theories (El-Samny 2008). Table 2 indicates nano architecture applications in building production.

Table 2: Nanoarchitecture applications in building production (Elvin 2007; Sagadevan 2013). 


\begin{tabular}{ll} 
& - Aerogel \\
- Thin-film insulation \\
- Thermal insulation: Vacuum insulating panels (VIPs) \\
- Temperature regulation: Phase changing materials(PCMs) \\
- Self-cleaning coatings: Lotus-effect and photo catalysis \\
- Easy to clean -ETC \\
- Anti-fogging \\
- UV and solar protection \\
- Anti-graffiti coatings \\
- Anti-reflective coatings \\
- Anti-fingerprint coatings \\
- Scratch-resistant coatings \\
- Anti-corrosion coatings \\
- Antimicrobial coatings \\
- Moisture resistance coatings \\
- Fire-proof coatings \\
- Light emitting diodes - LEDs \\
- Organic light emitting diodes - OLEDs \\
- Inorganic silicon solar cells \\
- Organic thin-film solar nanotechnologies \\
\hline Lighting & • Concrete - steel - wood \\
\hline Solar energy & - Glass - roofing - drywall - plastics and polymers \\
\hline Structural materials &
\end{tabular}

\subsubsection{Nano insulations}

Important quantities of energy are wasted in the buildings because of poor insulation. Energy saving materials are used in buildings to keep indoor temperatures at constant levels, resulting the decrease in $\mathrm{CO}_{2}, \mathrm{NO}_{2}$ and greenhouse gases in protecting the environment. These materials like fiberglass, rock wool and slag wool can be adapted to any shape, size or surface in order to provide a resistant path to the flow of heat. Nanoinsulation materials are produced aiming better alternatives to this area in the form of aerogels, vacuum insulation panels (VIPs) and phase changing materials (PCMs).

Aerogel: Aerogel is often known as frozen smoke, particularly utilized in building products and oil/gas industries. It consists of $95 \%$ of air, in nano sized pores that repress heat transfer through the aerogel. It is made from grades of fuzzy to translucent and may be tailored to different environments. The benefits are:

- High light transmission, $75 \%$ through $\mathrm{cm}$.

- Thermal conductivity is low $R$-value of eight inches, U-value of $71 \mathrm{~W} / \mathrm{m} 2 \mathrm{~K}$.

- Reduce the gain of solar heat and the spread of noise by sound attenuation.

- Durable to resist the change of color, performance degradation and mold.

- Capable to reduce the waste of building energy and carbon footprint.

- Has an excellent light diffusion and reducing of solar transmission, low weight: 60-80 $\mathrm{kg} / \mathrm{m}^{3}$.

- Architectural flexibility, aesthetically appealing and UV resistant (Baetens et al. 2011).

Thin-film insulation: Thin films are very thin layers of material which are extended from nanometer fractions single layer to multi micrometers in thickness. The most applications which represent thin films are, optical coatings and digital semiconductor gadgets 
(Schodek et al. 2009). They can be used as nano coating insulation which can be applied on glass and fabrics. For instance, masa shade curtains are fiber sheets which are covered with a nanoscale stainless steel film. Due to the potential to imbibe infrared rays from stainless steels, the curtains will be capable of blocking the sunlight, lowering in summer the temperatures of room $2-3^{\circ} \mathrm{C}$ better than traditional products and decrease the costs of electrical use in air conditioning (Elvin 2007). Heat absorbing films can be applied to windows providing cost effective control of heat and energy loads in building. Benefits encompass the capability to block solar heat and as much as $99 \%$ of UV rays whilst allowing seen light to pass through (Chopra et al. 2004).

Vacuum insulating panels (VIPs): The thin vacuum insulation panels (VIPs) consist of an enveloping skin enclosing the fill material in a vacuum. The skin is made of plastic foil often coated with aluminum or of stainless steel. The porous and pressure resistance fill material in different forms like foam, powder or glass fibers can be evacuated. They provide very good thermal insulation up to ten times better than conventional insulation materials. The applications are; new building constructions, conversion and renovation works, on the walls and floors (Atwa et al. 2015).

Phase changing materials (PCMs): Phase changing materials (PCMs) have good thermal retention. It is possible to use them both in new constructions and in old or existing buildings to keep the indoor temperature at ideal level. Latent energy is stored when the material changes its physical state, from solid to liquid or from liquid to gaseous. The latent warmth or cold performs a buffer function and can be used for temperature regulation, enabling the indoor temperature to be regulated mostly passively which results in significant energy savings. The switching temperature in which the phase changes occurs in latent heat storing materials designed for construction is defined as $25^{\circ} \mathrm{C}$. To regulate a $5^{\circ} \mathrm{C}$ increase in indoor temperature, $1 \mathrm{~mm}$ of PCM is required compared with $10-40 \mathrm{~mm}$ of concrete. They can be integrated into conventional building materials like plasters, plasterboards and aerated concrete blocks with specific retention properties. They are recyclable and biologically degradable materials (Atwa et al. 2015).

\subsubsection{Nano coatings}

The area of research on nanotechnology coatings are considered as the most widespread studies, that can be applied on concrete, glass and steel. Most of the coatings include Chemical Vapor Deposition (CVD), spray and plasma coating in order to create bonding with the base of material by producing a layer above it to provide surface of functional properties. One of the most important goal is to make self healing possible to achieve by the procedure of self-assembly coatings, in fact are very skinny coverings which are located on the material's surface in order to develop it's appearance or characteristics surface, such as using coatings to improve sturdiness or adding characteristics which offer protection to the material or resistance of corrosion. Its also possibly used to exchange the quality of adhesion, reflection and coloration (Elvin 2007; Schodek et al. 2009; Mehrabian, 2013; Vigneshkumar 2014).

\section{Self-cleaning coatings}

-Self-cleaning (Lotus-Effect): The first investigation of the self-cleaning surfaces was in the Seventies by botanist Wilhelm Barthlott. He had noted that his research on self-cleaning effect not only located in oriental Lotus plant leaves, also in European Nasturtium and the 
South African Myrtle Spurge (Elvin, 2007). He discovered the common character between all. At the microscopic range, they show a water repellent surface because of small knobbles or spikes they covered. With the assist of nanotechnology, manufactured lotus surfaces had been created. The lotus effect is useful in the places that exposed to the water in the way of staying clean and decreasing in the repairing demands ( $\mathrm{Lu} 2017)$.

- Self-cleaning (Photocatalytic): Photocatalytic coatings contains nanoparticles titanium dioxide $\left(\mathrm{TiO}_{2}\right)$. It works by a photocatalysis procedure which breaks the dirt by exposing it to the UV rays of sun and cleaned away with rain water (Schodek et al. 2009; Vigneshkumar 2014)).

Easy-to-clean (ETC): Easy-to-clean surfaces are smooth and water repellent. Their surface attraction force is low. A decrease in their surface energy results in diminished surface adhesion, repel water by forming droplets and running off. ETC surfaces are hydrophobic and oleophobic (Vigneshkumar 2014). They can be applied on masonry, timber, metal, concrete, textiles, leather, bath cabinet glazing and sanitary installations.

Anti-fogging: It happens by using nanoscalar $\mathrm{TiO}_{2}$ in ultra-thin coating, which has high attraction of wetness due to high surface energy it has. Ultra-thin film layer will be formed on the wet surfaces, in fact it's still on the surface but invisible because the film is transparent and gives a clear look. These coatings are used on bathroom mirrors, on the glass in the room which uses air-conditioning and can also be applied on plastics (Leydecker 2008).

Ultraviolet $(U V)$ and solar protection: UV protection coatings are made of industrial and organic additives. The two kinds are utilized in combination. The first one is applied to the upper layer in the form of a protecting lacquer, that's because it works on absorbing UV in order to filter the harm rays from sunlight before arriving at the surface of materials. The second one is different than the first one. Its influence came at a later stage and named as free-radical scavengers (Leydecker 2008). The electrochromic glass on the buildings needs no continuous electric current, it only needs one switch to change the transmission of light from darkness to transparency. The best solution to coloring glass is the photochromatic glass, due to that takes less time than the ultra-thin nano coating. It automatically changes to the darker just when it contacts with the sunlight with no need to switch it manually (Mehrabian 2013).

Anti-graffiti: Nanotechnology achieve a new method to preserve the building fabric by using anti-graffiti coatings. These coatings are highly effective and have the ability to make materials water resistant. They can be utilized on highly absorbent and porous materials like concrete, brick, lime and sandstone. They also allow materials to maintain their vapor permeability without closing the pores in materials and avoiding the damage from moisture (Rossi 2015).

Anti-reflective: The particles of the transparent nanoscalar surface according to the wavelength of light are much smaller. Silica glass capsules are used in nanoporous antireflective coatings with a thickness of $150 \mathrm{~nm}$ that are also able to reflect the invisible spectrum of light. The reflected light ratio can be reduced from $8 \%$ to $1 \%$ or less. Another cost-effective method is the moth-eye effect which is one of the anti-reflective surfaces methods used to reduce reflections at the night (Leydecker 2008).

Anti-fingerprints: Fingerprints became almost invisible by covering the surfaces with an anti-fingerprints coating. The coating will change the refraction of light on the surface and the reflections of light will give a smooth appearance to the glass or steel, which will make feel the surface cleaner. This coating is very flexible with the material which is installed on 
it, so if bent or twist the material, it will go with it without breaking or fracturing, this would be very helpful in order to use it in any different shape. Usually, it's used on furniture and elevators. The benefits are; maintain the clean appearance, decrease in the cost of cleaning and having the ability to resist scratching (Rossi 2015).

\subsubsection{Lighting}

Lighting applications consumes about one-third of the total energy use of the buildings. The conventional light sources create heat emissions which affects the room temperature that lead to increase the cooling costs of the room. Incandescent lighting lose approximately $95 \%$ of their energy on heat. Fluorescent lights use less energy but contain harmful metals like mercury. More efficient lights such as light-emitting diodes (LEDs) and organic light-emitting diodes (OLEDs) are produced to save energy (Elvin 2007).

Light-emitting diodes (LEDs): The diode is the device which made from two conducting materials and allows for the current to pass in only one direction. When electricity across by diode, the atoms accelerate to the higher level of energy, when the atoms transfer the electrons to the second material, energy releases and the light will be created (Baretz \& Tischler 2003). The properties of LEDs are;

- More efficient sources of light than incandescent bulbs because they produce more light in one watt and the performance will not change according to the size or shape.

- No need to the color filters to color the light, they can emit the needed color of light.

- Very small reaching to $2 \mathrm{~mm}^{2}$ and smaller.

- Can be quickly turn on and off.

- They don't generate heat or may be a little in infrared form which can only harm the fabrics or some sensitive materials.

- Durable and shockproof, have a long life span, evaluated between 35,000 to 50,000 hours or more (Baretz \& Tischler 2003); Schubert 2018; [2].

Organic light-emitting diodes (OLEDs): When the LED's emissive electroluminescent layer is formed from a film of organic (carbon) compound, then it's called OLED. The layers of organic semiconductor material are established between two electrodes, which one of them is transparent. The efficiency, lifetime and the emission of light depends on the structure of the device and the kind of materials used (Kulkarni et al. 2004; Kumar et al. 2019). The properties of OLEDs are;

- Very thin and flexible, can be located on any shape and can cover big areas.

- Because of their high flexibility, they are very desirable from different users.

- Have a lot of colors and high quality in the emission light (Kulkarni et al. 2004; Kumar et al. 2019).

\subsubsection{Solar energy}

Sunlight is the most abundant energy source on the earth. Nanotechnology brings economic and effective methods to change this renewable energy to electricity. The advantages of nanotechnology in this field can be seen in two main applications which are; Silicon solar cells: Silicon nanowires are used in producing solar cells that produce power which are installed in a polymer to decrease the cost and increase the productivity.

Thin-film solar nanotechnologies: Nanotechnology is the basis for advances in silicon-based photovoltaics, new nanocrystal materials, thin film materials and conductive polymeric films 
(Morton 2006). The organic thin films are generally depending on the polymers and nanoparticles which are materials that don't cost much. Flexibility is one of the features that make them easy and perfect to use in any application of the building. This feature provides a great opportunity to work on new architectural ideas and concentrate on the aesthetic side, which was hard to do with the normal flat panels (Atwa et al. 2015).

\subsection{Analysis of Nanomaterials}

The advantages and disadvantages (positive and negative effects) in different applications of nanomaterials used in building production can be summarized in Table 3 in relation with environment-human health and energy-resource conservation. This table helps to explain the relation between nanotechnology and sustainability and how nanotechnology can participate in achieving sustainability (Ylmaz \& Vural, 2015).

Table 3: Analysis of nanomaterials in building production within the context of sustainability

\begin{tabular}{|c|c|c|}
\hline NANOMATERIALS & ADVANTAGES (+ effect) & DISADVANTAGES(- effect) \\
\hline $\begin{array}{l}\text { Insulations } \\
\text { - Aerogel } \\
\text { - Thin film insulation } \\
\text { - Thermal insulation: VIPs } \\
\text { - Temperature regulation: } \\
\text { PCMs }\end{array}$ & $\begin{array}{l}\text {-High heat insulation value provides effective energy conservation } \\
\text {-Reduce consumption of resources } \\
\text {-Take up less space than traditional insulators } \\
\text {-Reduce transportation costs } \\
\text {-Reduce the amount of harmful gas } \\
\text {-Indoor thermal balance remains at ideal level }\end{array}$ & \multirow{4}{*}{$\begin{array}{l}\text {-New and expensive products. } \\
\text {-Special knowledge and } \\
\text { experience needed in terms of } \\
\text { usage } \\
\text {-Difficulties in production and } \\
\text { observation with nanoscale } \\
\text {-Insufficient information on } \\
\text { their continuity has been } \\
\text { obtained } \\
\text {-Special production, control and } \\
\text { repair methods are needed } \\
\text {-Difficult to evaluate the effect } \\
\text { of nanoparticles in the } \\
\text { environment to follow the } \\
\text { traces of the ecosystems } \\
\text {-The effects on human health } \\
\text { and environment have not been } \\
\text { fully determined } \\
\text {-Meaning standards and test } \\
\text { methods are not fully clarified }\end{array}$} \\
\hline $\begin{array}{l}\text { Coatings } \\
\text { - Self-cleaning } \\
\text { - Easy to clean } \\
\text { - Anti-fogging } \\
\text { - UV \& solar protection } \\
\text { - Anti-graffiti } \\
\text { - Anti-reflective } \\
\text { - Anti-fingerprint } \\
\text { - Scratch resistant } \\
\text { - Anti-corrosion } \\
\text { - Anti-microbial } \\
\text { - Moisture resistance } \\
\text { - Fire-proof }\end{array}$ & $\begin{array}{l}\text {-Reduce the time of working on cleaning } \\
\text {-Reduce the need for artificial illumination } \\
\text {-Reduce material consumption by extending the service life } \\
\text {-Increase air quality } \\
\text {-Prevent the spread and formation of the bacteria } \\
\text {-Reduce the use of chemical substances in the cleaning process } \\
\text {-Reduce the formation of harmful gases which pollute the } \\
\text { environment by making the harmful components in the air } \\
\text { harmless } \\
\text { - Don't contain any harmful substances }\end{array}$ & \\
\hline $\begin{array}{l}\text { Lighting } \\
\text { - Light Emitting Diodes } \\
\text { (LEDs) } \\
\text { - Organic Light Emitting } \\
\text { Diodes (OLEDs) }\end{array}$ & $\begin{array}{l}\text {-Reduce the amount of energy for lighting } \\
\text {-Don't need or less need maintenance, provide high efficiency and } \\
\text { brightness } \\
\text {-Have long lifespan and high impact strength } \\
\text {-Reduce cooling costs } \\
\text {-Don't need to the color filters to color the light, LEDs can emit } \\
\text { the color of light needed } \\
\text {-OLEDs are very thin and flexible, can be located on any shape } \\
\text { - Don't contain a harmful substance like mercury to the } \\
\text { environment and human health } \\
\text {-Prevent energy loss and conserve energy } \\
\text {-Indoor thermal balance remains at ideal level } \\
\text {-Provide enough natural lighting }\end{array}$ & \\
\hline $\begin{array}{l}\text { Solar energy } \\
\text { - Inorganic silicon solar } \\
\text { cells } \\
\text { - Organic thin film solar } \\
\text { nanotechnologies }\end{array}$ & $\begin{array}{l}\text {-High efficiency and wide use areas } \\
\text {-Restrict the use of exhausted fuels } \\
\text {-Increase the use of renewable energy } \\
\text {-Save energy and reduces energy costs } \\
\text {-Prevent energy losses } \\
\text {-Reduce the release of harmful gases } \\
\text {-Reduce consumption of raw materials }\end{array}$ & \\
\hline
\end{tabular}

\subsection{Test Matrix and Evaluation of Nanomaterials}

According to the analysis of nanomaterials in building production within the 
context of sustainability in Table 3 , a test matrix is made. The matrix evaluates the different applications of nanomaterials under the criteria of sustainability (Table 4). The advantages are marked as positive, disadvantages as negative and unknown or ineffective as null value.

Table 4: The test matrix of nanomaterials (Çă̆nan \& Özer 2014; Dfatade 2014; Yılmaz \& Vural 2015)

\begin{tabular}{|c|c|c|c|c|c|c|c|c|c|c|c|c|c|c|c|c|c|c|c|c|c|c|}
\hline \multirow{4}{*}{ 㘯 } & \multirow{4}{*}{\multicolumn{2}{|c|}{$\begin{array}{l}\text { NANOMATERIAL APPLICATIONS } \\
\text { IN BUILDING PRODUCTION }\end{array}$}} & \multicolumn{20}{|c|}{ NANOMATERIALS } \\
\hline & & & \multicolumn{4}{|c|}{ Insulations } & \multicolumn{12}{|c|}{ Coatings } & \multicolumn{2}{|c|}{ ighting } & \multicolumn{2}{|c|}{$\begin{array}{l}\text { Solar } \\
\text { energy }\end{array}$} \\
\hline & & & $\begin{array}{l}\bar{\Phi} \\
\text { g. } \\
\mathrm{g} \\
\mathrm{D} \\
\square \\
\end{array}$ & 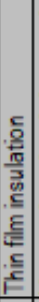 & 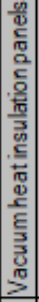 & 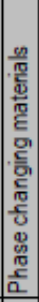 & 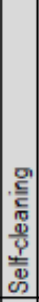 & 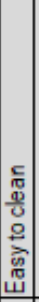 & 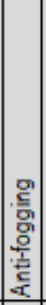 & 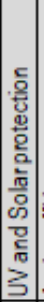 & 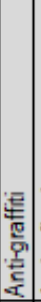 & 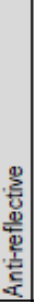 & 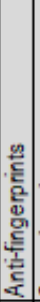 & 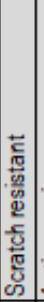 & 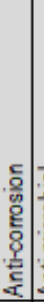 & 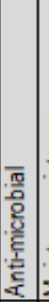 & $\begin{array}{l}\frac{8}{8} \\
\frac{c}{0} \\
\frac{0}{5} \\
\frac{5}{5} \\
\frac{2}{2} \\
\frac{2}{2} \\
\frac{2}{3} \\
\frac{2}{2} \\
\frac{0}{2}\end{array}$ & 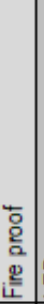 & 总 & 总 & 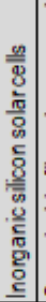 & 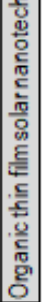 \\
\hline & & & 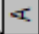 & $\infty$ & 0 & 0 & ш & 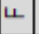 & ○ & $\mp$ & - & $\supset$ & $\simeq$ & - & $\Sigma=$ & $z$ & 010 & a. & $\propto$ & $\infty 1$ & $\vdash$ & $\supset$ \\
\hline \multirow{9}{*}{ 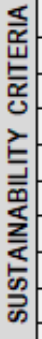 } & 1 & Prevent energy loss and conserves energy & + & + & + & + & + & + & + & + & + & + & + & + & + & + & + & + & + & + & + & + \\
\hline & 2 & Reduce natural resource consumption & + & + & + & + & + & + & + & + & + & + & + & + & + & + & + & + & + & + & + & + \\
\hline & 3 & Take up less space than tradifonal mateials & + & + & + & + & + & + & + & + & + & + & + & + & + & + & + & + & + & + & + & + \\
\hline & 4 & Reduce transportation costs & + & + & + & + & + & + & + & + & + & + & + & + & + & + & + & + & + & + & + & + \\
\hline & 5 & Reduce production of harmful gases to environment & + & + & + & + & + & + & + & + & + & + & + & + & + & + & + & + & + & + & + & + \\
\hline & 6 & Keep indoor thermal balance at ideal level & + & + & + & + & 0 & 0 & + & + & 0 & + & 0 & 0 & 0 & 0 & + & $\circ$ & + & + & $\circ$ & 0 \\
\hline & 7 & Reduce the time of woxing on cleaning & 0 & + & 0 & 0 & + & + & + & + & + & + & + & + & ++ & + & + & + & 0 & $\circ$ & $\circ$ & 0 \\
\hline & 8 & Long lifespan / Ease of application / Durable & + & + & + & + & + & + & + & + & + & + & + & + & + & + & + & + & + & + & + & + \\
\hline & 9 & Increase in air quality & + & + & + & + & + & + & + & + & + & + & + & + & + & + & + & + & + & + & 0 & 0 \\
\hline \multirow{4}{*}{ 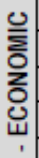 } & 10 & Prevent the spread and formation of bacteria & + & + & + & + & + & + & + & + & + & + & + & + & + & + & + & + & $\circ$ & 0 & 0 & $\circ$ \\
\hline & 11 & Reduce use of chemical substances in cleaning & + & + & + & + & + & + & + & + & + & + & + & + & ++ & + & + & + & + & + & + & + \\
\hline & 12 & Don't contain harmful substances to enviroment & + & + & + & + & + & + & + & + & + & + & + & + & + & + & + & + & + & + & + & + \\
\hline & 13 & No or less need repair and maintenance & + & + & + & + & + & + & + & + & + & + & + & + & + & + & + & + & + & + & + & + \\
\hline Lُ & 14 & High efficiency and wide use area & + & + & + & + & + & + & + & + & + & + & + & + & + & + & + & + & + & + & + & + \\
\hline \multirow{10}{*}{ 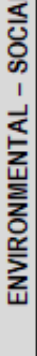 } & 15 & Increase the use of renewable energy & + & + & + & + & + & + & + & + & + & + & + & + & + & + & + & + & + & + & + & + \\
\hline & 16 & Saves energy and reduces energy costs & + & + & + & + & + & + & + & + & + & + & + & + & + & + & + & + & + & + & + & + \\
\hline & 17 & Reusable & + & + & + & + & 0 & 0 & 0 & 0 & 0 & 0 & $\circ$ & o & 0 & $\circ$ & 0 & 0 & + & + & + & + \\
\hline & 18 & Recyclable & + & + & + & + & 0 & 0 & 0 & 0 & 0 & 0 & 0 & 0 & 0 & o & 0 & $\circ$ & + & + & + & + \\
\hline & 19 & New and expensive products & - & - & - & - & - & - & - & - & - & - & - & - & - & - & - & - & - & - & - & - \\
\hline & 20 & Special knowledge \& experience need to use & - & - & - & - & - & - & - & - & - & - & - & - & - & - & - & - & - & - & - & - \\
\hline & 21 & Difficult to produce and observe on nanoscale & - & - & - & - & - & - & - & - & - & - & - & - & - & - & - & - & - & - & - & - \\
\hline & 22 & Meaning standards \& test methods aren't clarfied & - & - & - & - & - & - & - & - & - & - & - & - & - & - & - & - & - & - & - & - \\
\hline & 23 & Effects on human health haven't been determined & - & - & - & - & - & - & - & - & - & - & - & - & - & - & - & - & - & - & - & - \\
\hline & 24 & Effects on environment/ecosystem not determined & - & - & - & - & - & - & - & - & - & - & - & - & - & - & - & - & - & - & - & - \\
\hline \multicolumn{23}{|c|}{$\begin{array}{cc}\text { Test marking key: } & (+) \text { : positive effect } \\
\text { Test results: } & 65.2 \%\end{array}$} \\
\hline
\end{tabular}

Evaluation report: After testing the most common applications of nanomaterials in building production in relation with environmental, economic and social sustainability criteria, the results showed that the advantages are 2.7 times more than the disadvantages. The positive effect ratio was estimated at $65.2 \%$, while the negative effect was $24.2 \%$ and $10.6 \%$ has no effect or not known yet. The positive results pointed out that nanomaterials 
can prevent losing energy, conserves energy, reduce natural resource consumption, take up less space than traditional materials and the transportation costs are less. Applying nanomaterials reduce the production of harmful gases to the environment, keep the indoor thermal balance at ideal level of the user, reduce the time of cleaning and the use of chemical substances in cleaning. They have a long lifespan, ease of application and don't need or less need for repairing and maintenance. Indoor applications result with an increase in the air quality and prevention the spread of bacteria. Nano lighting products reduce the use of energy for lighting, high efficiency and brightness, reduces the cooling costs of space, no need for color filters to change the color and saves energy. Because the products of nanomaterials are new technology, most of them are still expensive and need special knowledge to be used in building production. It seems that the application of nanomaterials can be useful in achieving sustainability, protect and enhance the environment but the effects on human health have not been fully determined yet and this is the most important disadvantage of using these new tech materials.

\section{Conclusion}

In this paper, nanomaterials used in architecture field are examined and their different effects on sustainability are determined with the help of a test matrix (Table 4). The findings show that, the positive effects are 2.7 times more than the negative effects which is $65.2 \%$ positive and $24.2 \%$ negative while $10.6 \%$ is ineffective or not known yet. Together with these positive effects, there are still unknown effects on human health, especially in their production stages. Generally, they can be considered as helpful and suitable for achieving sustainability but their misuse have the potential to harm human health and environment. Conclusively, a regulatory system is needed to identify the sustainable nanomaterials and avoid harmful construction materials to be used in building production.

The paper clarifies the applications that's offered by nanomaterials in building production and examines these new materials from the point of view of architects and sustainability. The study is concluded with the aim of contributing to the literature bank of nanomaterials research.

\section{Acknowledgement}

This article is generated from the master's thesis entitled The Availability of Nanomaterial for Building Production in the Context of Sustainability, prepared by Ahmad Zeyad Aljenbaz at the Near East University, under the supervision of Assist. Prof. Dr. Çiğdem Çă̆nan.

\section{References}

Aljenbaz, Z. A. (2017). The Availability of Nanomaterial for Building Production in the Context of Sustainability, Master Thesis. Near East University, Nicosia, Cyprus. 
Arcan, E. F., and Evci, F. (1999). Mimari Tasarıma Yaklaşım: Bina Bilgisi Çalışmaları. TasarımYayın Grubu. Istanbul.

Atwa, M., Al-Kattan, A., and Elwan, A. (2015). Towards Nano Architecture: Nanomaterial in Architecture A Review of Functions and Applications. International Journal of Recent Scientific Research, (6),4, 35513564.

Baetens, R., Jelle, B. P. and Gustavsen, A. (2011). Aerogel insulation for building applications: a state-of-theart review. Journal of Energy and Buildings, 43(4), 761-769.

Baretz, B., and Tischler, M. A. (2003). U.S. Patent No. 6,600,175. Washington, DC: U.S. Patent and Trademark Office.

Berger, M. (2010). Nanotechnology and the future of advanced materials. http://www.nanowerk.com/spotlight/spotid=16047.php 2010. Accessed 17/04/2018.

Chopra, K. L., Paulson, P. D., \& Dutta, V. (2004). Thin-film solar cells: an overview. Progress in Photovoltaics: Research and Applications, 12(2-3), 69-92. https://doi.org/10.1002/pip.541.

Çağnan, Ç. \& Özer, H. (2014). A Model for Testing the Performance of Building Products in Conjunction with Environmental-Ecological and Legal Obligations Using The Systems Approach in Building Production. Megaron Journal, 9(4), 255-270.

Dfatade-O, M. (2014). Application of Nanotechnology and its Impacts on Building Materials in the UK Construction Industry. Doctoral Thesis, University of Bolton, Bolton, England.

El-Samny, M. F. (2008). Nano Architecture - Nanotechnology and Architecture (Master's Thesis), University of Alexandria. In Proceedings of NSTI Nanotechnology Conference.

Elvin, G. (2007). Building green with nanotechnology. In Proceedings of NSTI Nanotechnology Conference.

Kulkarni, A. P., Babel, T. A. and Jenekhe, S. A. (2004). Electron Transport Materials for Organic LightEmitting Diodes. Chemistry of Materials. 16(23), 4556-4573. DOI: 10.1021/cm0494731.

Kumar S. A, Shankar J. S, Periyasamy B. K. and Nayak K. S. (2019). Device engineering aspects of Organic Light-Emitting Diodes (OLEDs). Polymer-Plastics Technology and Materials, bttps:// doi.org/10.1080/25740881.1563133

Leydecker, S. (2008). Nano Materials: in Architecture, Interior Architecture and Design. Birkhäuser, Basel.

Loeve, S. (2010). About a definition of nano: how to articulate nano and technology. HYLE-International Journal in Philosophy of Chemistry, 16(1), 3-18.

Lu, Y. (2017). Robust Self-cleaning Coatings. Doctoral Thesis. University College London. discovery.ucl.ac.uk. Accessed 17/04/2018.

Mehrabian, S. (2013). Nanotechnology Applications in the Construction Industry. Journal of Basic and Applied Scientific Research, 3(6), 391-396.

Mohamed, A. S. Y. (2015). Nano-Innovation in Construction, a New Era of Sustainability. International Conference on Environment and Civil Engineering (ICEACE'2015). Pattaya, Thailand.

Morton, O. (2006). Solar energy: A new day dawning? Silicon Valley sunrise. Journal of Nature, 443(7107), 1922.

Richter, J., Seidel, R., Kirsch, R., Mertig, M., Pompe, W., Plaschke, J., and Schackert, H. K. (2000). Nanoscale palladium metallization of DNA. Journal of Nanoscale, 94, 8720.

Rossi, C. (2015). Al-based Energetic Nano Materials: Design, Manufacturing, Properties and Applications. Hoboken, New Jersey: John Wiley \& Sons.

Sagadevan, S. (2013). Recent Trends On Nanostructures Based Solar Energy Application: A Review. Reviews on Advanced Materials Science, 34: 44-61.

Schodek, D. L., Ferreira, P. and Ashby, M. F. (2009). Nanomaterials, Nanotechnologies and Design: An Introduction for Engineers and Architects. Butterworth-Heinemann. Elsevier. ISBN: 978-0-7506$8149-0$

Schubert, E. F. (2018). Light Emitting Diodes (3rd Ed.). Troy, New York, USA. https://books.google.com.cy/books?isbn=0986382663. Accessed 04/06/2018.

Tamirat, Y. (2017). The Role of Nanotechnology in Semiconductor Industry: Review Article. Journal of Material Science \& Nanotechnology, 5(2):202.

Vigneshkumar, C. (2014). Study on Nanomaterials and Application of Nanotechnology and Its Impacts in Construction. Discovery, 23(75), 8-12.

Williams, D. E. (2007). Sustainable design: Ecology, architecture and planning. Hoboken: John Wiley \& Sons. 
Yılmaz, S. and Vural, N., (2015). Sürdürülebilir Yapıların Tasarlanmasında Nanoteknolojinin Rolü - Role of Nanotechnology in the Design of Sustainable Buildings. In Proceedings of the $2^{\text {nd }}$ International Conference on Sustainable Building, (pp. 294-302). Ankara: Gazi University.

[1] Report of the World Commission on Environment and Development. https://www.sswm.info/sites/default/files/reference_attachments/UN\%20WCED\%201987\%20 Brundtland\%20Report.pdf. Accessed 02/26/2018.

[2] http://www.edisontechcenter.org/LED.html. Accessed 03/08/2019. 